\title{
Amniotic Fluid Embolism - A Case Report
}

\author{
Vijay Kumar $\mathbf{A G}^{2}$, Vinay $\mathbf{J}^{1^{*}}$, M G Shivaramu ${ }^{3}$, Kumar $\mathbf{U}^{4}$, Somashekar ${ }^{1}$ \\ ${ }^{1}$ Assistant professor, Department of Forensic Medicine and Toxicology, Adichunchanagiri Institute of Medical \\ Sciences, Bg Nagara, Nagamangala Taluk, Mandya District, Karnataka, India \\ ${ }^{2}$ Associate professor, Department of Forensic Medicine and Toxicology, Adichunchanagiri Institute of Medical \\ Sciences, Bg Nagara, Nagamangala Taluk, Mandya District, Karnataka, India \\ ${ }^{3}$ Professor \& Principal, Department of Forensic Medicine and Toxicology, Adichunchanagiri Institute of \\ Medical Sciences, Bg Nagara, Nagamangala Taluk, Mandya District, Karnataka, India \\ ${ }^{4}$ Professor, Department of Forensic Medicine and Toxicology, Adichunchanagiri Institute of Medical Sciences, \\ Bg Nagara, Nagamangala Taluk, Mandya District, Karnataka, India
}

*Corresponding Author: Vinay J, Assistant professor, Department of Forensic Medicine and Toxicology, Adichunchanagiri Institute of Medical Sciences, Bg Nagara, Nagamangala Taluk, Mandya District, Karnataka, India. Email: vijay.fmt@ rediffmail.com

\begin{abstract}
An amniotic fluid embolism (AFE) is a rare childbirth (obstetric) emergency in which amniotic fluid enters the blood stream of the mother to trigger a serious reaction. This reaction then results in cardiorespiratory (heart and lung) collapse and massive bleeding (coagulopathy).[1] A 32 year old lady elderly primi with 39 weeks of gestation with cephalic presentation with precious pregnancy with polyhydromnios brought by relative's to the local hospital. Patient was taken to LSCS and live male baby was extracted by gynecologist. Liquor clear and excess, placenta and membranes removed manually, uterus feel flabby. No evidence of post-partum hemorrhage or tear. HISTO-PATHOLOGY REPORT: lungs show features of pulmonary oedema, interstitial inflammation and foci of hemorrhagic infarct. AFE is diagnosed when all other causes have been excluded. The presence of fetal squamous cells or other fetal tissues, including meconium have been found in the maternal circulation after the event. Diagnosis is also based upon the signs and symptoms observed during the birth or procedures.
\end{abstract}

Keywords: amniotic fluid embolism, caesarian section, polyhydromnios, pulmonary edema, interstitial inflammation, hemorrhagic infarct.

\section{INTRODUCTION}

An amniotic fluid embolism (AFE) is a rare childbirth (obstetric) emergency in which amniotic fluid enters the blood stream of the mother to trigger a serious reaction. This reaction then results in cardiorespiratory (heart and lung) collapse and massive bleeding (coagulopathy).[1]

Amniotic fluid embolism is suspected when a woman giving birth experiences very sudden insufficient oxygen to body tissues, low blood pressure, and profuse bleeding due to defects in blood coagulation. Though symptoms and signs can be profound, they also can be entirely absent. There is much variation in how each instance progresses. [2, 3]

AFE is very rare and complex. The disorder occurs during the last stages of labor when amniotic fluid enters the circulatory system of the mother via tears in the placental membrane or uterine vein rupture. [4]

Upon later analysis, fetal cells are found in the maternal circulation. When the fetal cells and amniotic fluid enters the bloodstream, reactions occur that cause severe changes in the mechanisms that affect blood clotting.

Disseminated intravascular coagulation occurs and results in serious bleeding. The condition can also develop after elective abortion, amniocentesis, cesarean delivery or trauma. Small lacerations in the lower reproductive tract are associated with AFE.

The use of drugs to induce labor, such as misoprostol, nearly doubles the risk of AFE. A maternal age of 35 years or older is associated with AFE. [5] 
Amniotic fluid embolism is very uncommon and the rate at which it occurs is 1 instance per 20,000 births. Though rare, it comprises $10 \%$ of all maternal deaths.

\subsection{Risk Factors}

Many factors are associated with increased risk, but evidence is inconsistent. As with exposure to fetal antigens, many of the risk factors are commonplace or at least much more likely than amniotic fluid embolism, and there is no good pathophysiologic understanding of why only a few women with risk factors develop the syndrome. Nonetheless, risk is generally thought to be increased by the following:

- Cesarean Delivery

- Polyhydramnios

\section{CASE Report}

On April 2019 we received a deceased body of 32 year old female, for post mortem examination at department of forensic medicine \& toxicology, Adichunhanagiri Institute of Medical Sciences, B G nagar.

\section{HISTORY}

A 32 year old lady elderly primi with 39 weeks of gestation with cephalic presentation with precious pregnancy with polyhydromnios brought by relative's to the local hospital. Patient was taken to LSCS and live male baby was extracted by gynecologist. Liquor clear and excess, placenta and membranes removed manually, uterus feel flabby. No evidence of post-partum hemorrhage or tear.

On examination patient blood pressure drops to 70/30 mmhg, pulse 52/minute, spo2 65\% and patient was non-responsive. CPR initiated with adrenaline and intubated. Then patient was referred to higher centre accompanied by gynaecologist and anesthetist. But on the way to higher centre patient was declared dead.

Medico-legal-case intimation was sent to nearest police station and inquest report was prepared by concerned police under section 174 cr.p.c.

\section{Postmortem Findings}

The deceased body is of a female, aged about 33 years, moderately built and nourished, measuring 5'5" in length with black colored scalp hair.

Both the eyes are closed and pupils are dilated and fixed.
Rigor mortis present all over the body.

Post-mortem staining is present at the back.

Transverse Surgically stitched wound (6 stitches) of $18 \mathrm{~cm}$ presents $3 \mathrm{~cm}$ below the umbilicus.

Right lung-400grams, left lung-350 grams.

Both the lungs are congested and edematous. Cut section exudes frothy fluid mixed with blood.

Uterus: bulky and surgically stitched wound present. Uterine cavity is empty.

As a routine procedure heart, both the lungs, uterus, both the kidneys are forwarded to histopathology examination.

Histo-Pathology Report: lungs shows features of pulmonary edema, interstitial inflammation and foci of hemorrhagic infarct

\section{DISCUSSION}

AFE is diagnosed when all other causes have been excluded. The presence of fetal squamous cells or other fetal tissues, including meconium have been found in the maternal circulation after the event. Diagnosis is also based upon the signs and symptoms observed during the birth or procedures.

The most significant pathologic findings at autopsy are limited to the lungs. Grossly, the lungs show evidence of pulmonary edema (in $70 \%$ of the cases). Alveolar hemorrhage and pulmonary embolism of amniotic fluid materials are present; the presence of embolic particles is essential for diagnosis, but on histology they may be missed because of their small size.

Lung Frequent findings at autopsy included pulmonary edema, congestion, and focal atelectasis in AFE.

The clinical manifestation of AFE resembles both embolism and anaphylaxis. A reliable diagnosis could be made only upon histological evaluation; however, it is still nothing more than one of the necessary conditions for the diagnosis of AFE.

\section{Conclusion}

Amniotic fluid embolism syndrome is an infrequent, unpredictable, and catastrophic complication of pregnancy. It is virtually impossible to predict which patients are at risk for AFE. Diagnosis must be based on a spectrum of clinical signs and symptoms and by exclusion of other causes. Most cases of AFE 
are associated with dismal maternal and fetal outcomes, regardless of the quality of care rendered. Improved understanding of the pathophysiology of AFE may lead to the development of preventive measures and more effective and specific treatment.

\section{REFERENCES}

[1] Stafford, Irene, Sheffield, Jeanne (2007). "Amniotic Fluid Embolism". Obstetrics and Gynecology Clinics of North America. 34 (3): 545-553.

[2] Stein, Paul (2016). Pulmonary embolism. Chichester, West Sussex, UK Hoboken, NJ: John Wiley \& Sons Inc.
[3] Leveno, Kenneth (2016). Williams's manual of pregnancy complications. New York: McGrawHill Medical. pp. 223-224.

[4] Vinay K, Abul KA, Nelson F, Jon CA (201408-27). Robbins and Cotran Pathologic Basis of Disease, Professional Edition E-Book. Elsevier Health Sciences. pp. 129

[5] Kramer, Rouleau, Jocelyn, Baskett, Thomas F, Joseph (2006). "Amniotic-fluid embolism and medical induction of labour: a retrospective, population-based cohort study". The Lancet. 368 (9545): 1444-1448.

Citation: Vijay Kumar AG, Vinay J, M G Shivaramu, Kumar U, Somashekar. Amniotic Fluid Embolism - A Case Report. ARC Journal of Forensic Science. 2019 4(1):32-34. http://dx.doi.org/10.20431/2456-0049. 0401004

Copyright: () 2019 Authors. This is an open-access article distributed under the terms of the Creative Commons Attribution License, which permits unrestricted use, distribution, and reproduction in any medium, provided the original author and source are credited. 